\title{
BASIC ROLES OF SEX STEROID HORMONES IN WOUND REPAIR WITH FOCUS ON ESTROGENS (A REVIEW)
}

\author{
Čriepoková, Z. ${ }^{1}$, Lenhardt, L. ${ }^{1}$, Gál, $P^{2}{ }^{2,3,4,5}$ \\ ${ }^{1}$ Department of Pathological Anatomy, University of Veterinary Medicine and Pharmacy, Košice \\ ${ }^{2}$ Department for Biomedical Research, East-Slovak Institute of Cardiovascular Diseases, Inc., Košice \\ ${ }^{3}$ Department of Pharmacology, Faculty of Medicine, P. J. Šafárik University, Košice \\ ${ }^{4}$ Department of Pharmacognosy and Botany, Faculty of Pharmacy, Comenius University, Bratislava \\ The Slovak Republic \\ ${ }^{5}$ Institute of Anatomy, 1st Faculty of Medicine, Charles University, Prague \\ The Czech Republic \\ pgal@vusch.sk
}

\begin{abstract}
Previously, it has been shown that sex hormones, in particular estrogens, play an important role in the regulation of biological processes involved in tissue repair and regeneration. Accordingly, several studies have supported the beneficial properties of hormone replacement therapies (HRT) in postmenopausal models. The present review paper explores the potential for targeted sex steroid HRT as a new therapeutic option for the surgical management of wounds in postmenopausal women and animals.
\end{abstract}

Key words: androgens; estrogens; wound healing

\section{INTRODUCTION}

Wound healing, a biological process in the body, is achieved through four continuously overlapping phases: hemostasis, inflammation, proliferation, and remodeling
$[14,15]$. For a wound to heal successfully, all four phases should occur in a proper sequence with exact timing, and continue for a specific duration at optimal intensities [14, $15,25]$. Wound healing begins at the moment of injury and involves the interplay of many cell types, such as: neutrophils, macrophages, lymphocytes, keratinocytes, fibroblasts, endothelial cells, and adult stem cells. This process is regulated by several cytokines and chemokines and also includes extracellular matrix (ECM) depositions [15, 23, 27, 34].

Interruptions, aberrancies, or prolongation of selected phases involved in wound repair can lead to healing impairment and/or to development of non-healing chronic wounds $[15,34]$. Such wounds generally have failed to progress through the normal stages of healing and frequently enter a state of pathologic inflammation or lodge in the proliferative phase due to a postponed, incomplete, and/or uncoordinated inflammation and granulation tissue formation $[11,15,33,34]$.

Multiple factors can cause impaired wound healing by affecting one or more phases of the process and in general 
may be categorized into local and systemic. The influences of these factors are not mutually exclusive [15]. Single or multiple factors can play a role in any of individual phases, contributing to the overall outcome of the healing process [15].

Important local factors that influence the wound healing include: venous insufficiency, oxygenation, presence of infection and foreign body in the wound as well as localization, size, deepness, and the bed of the wound [15, 29]. Systemic factors affecting wound healing are: nutrition, sex steroid hormones, age, gender, stress, central hypoxia, hematologic disorders, obesity, diseases, such as diabetes, hereditary healing disorders, uremia, etc. [15, 29]. In addition to the above mentioned systemic factors; immunocompromised conditions during radiation therapy and/or administration of drugs such as glucocorticoids, NSAID and anti-tumor chemotherapy, also frequently lead to impaired wound repair $[15,29]$.

At present, it is widely accepted that aging is associated with delayed wound healing and that primary causative factor of this condition is not ageing alone, but a decline of estrogen circulating levels, as well as maintenance of circulating levels of testosterone and dihydrotestosterone. Hardman and Ashcroft [16] studies in the area of genetic human research have suggested that estrogen deprivation is the major factor controlling delayed healing in elderly humans. This study which wasconducted with the help of microarray techniques has shown that $78 \%$ of genes that are differentially expressed during wound healing in the young and elderly men are estrogen-regulated, while only $3 \%$ are age-associated, strongly implicating reduced estrogen, and not known geronto-genes, as the primary regulator of delayed healing in aged subjects. From this point of view, the sex steroid hormones (Table 1), in particular estrogen, are one of the main systemic factors affecting wound healing. In female animals, the chronic estrogen deprivation has been achieved by castrations and many researchers have corroborated impaired wound healing of the skin in the presence of the hypoestrogenic state.

\section{EFFECT OF ESTROGENS ON WOUND HEALING}

A shcroft et al. [6] demonstrated that estrogen deprivation in ovariectomized rats led to delayed and impaired wound healing as determined by: re-epithelialization time, wound width, and collagen deposition. However, topical estrogen application accelerated the healing rate as measured by: decreased re-epithelialization time, decreased wound width, and increased collagen deposition [6]. Such a situation may be found similar in humans. In this context, postmenopausal women with chronic estrogen deprivation have shown reduced rates of collagen deposition and reepithelialization of wounds compared with premenopausal women. Nonetheless, postmenopausal women taking HRT showed a similar rate of collagen deposition and re-epithelialization of wounds compared to premenopausal women, indicating that systemic estrogen replacement reversed delays in wound healing [6]. The role of estrogen in the acceleration of cutaneous healing was observed also in others studies conducted on OVX female mice where results were based mainly on the cytokine profile $[8,10,17]$.

\section{OBESITY AND ESTROGEN DEFICIENCY IN WOUND HEALING}

Obesity is a serious factor that negatively influence skin wound healing due to a relative hypoperfusion and ischemia that occurs in subcutaneous adipose tissue [1]. Estrogen is in some way implicated in the body metabolism because females with an absence of estrogen, lead to increased body weight gain [22]. Furthermore, in rodent studies, the systemic estrogen treatment of OVX mice has decreased the risk of gaining weight and body fat [36]. Holcomb et al. [18] showed that obesity in the absence of estrogen inhibited wound healing; however, obesity in the presence of ovarian hormones did not inhibited wound healing. Based on these data, it may be suggested that estrogen must have a direct regulatory role in wound repair, rather than only a protective action in developing obesity. On the other hand, in the same study, the authors have revealed that the lean phenotype is associated with improved wound healing regardless the estrogen status [18]. Implication of other research methods such as PCR, histopathology, and wound tensile strength measurement would probably better explain these tricky roles of estrogens in wound healing in the case of the lean phenotype. 
Table 1. Influence of sex steroid hormones on wound healing

\begin{tabular}{|c|c|c|c|c|c|c|c|}
\hline Species & Gender & Age & Hormonal status & Treatment & Wound healing & Wound type & References \\
\hline rats & female & young & OVX & & delayed & acute & 6 \\
\hline rats & female & young & OVX & $\begin{array}{c}\text { local application of } \\
\text { estrogen }\end{array}$ & accelerated & acute & 6 \\
\hline human & women & aged & postmenopausal & & impaired & acute & 6 \\
\hline human & women & aged & postmenopausal & HRT & accelerated & acute & 6 \\
\hline mice & female & young & $\begin{array}{l}\text { OVX coexisting } \\
\text { obesity }\end{array}$ & & inhibited & acute & 18 \\
\hline mice & female & young & $\begin{array}{l}\text { OVX lean } \\
\text { phenotype }\end{array}$ & & not inhibited & acute & 18 \\
\hline mice & female & young & $\begin{array}{l}\text { not OVX coexisting } \\
\text { obesity }\end{array}$ & & not inhibited & acute & 18 \\
\hline mice & female & young & OVX & DHEA & accelerated & acute & 26 \\
\hline mice & male & old & intact & DHEA & accelerated & acute & 26 \\
\hline mice & male & young & intact & DHEA & without effect & acute & 26 \\
\hline mice & $?$ & $?$ & $?$ & DHEA & $\begin{array}{c}\text { limited extend of } \\
\text { postburn tissue } \\
\text { necrosis }\end{array}$ & $\begin{array}{l}\text { thermal } \\
\text { injury }\end{array}$ & 4 \\
\hline mice & $?$ & $?$ & $?$ & estrogen & without effect & $\begin{array}{l}\text { thermal } \\
\text { injury }\end{array}$ & 4 \\
\hline mice & male & young & castrated & & markedly accelerated & acute & 7 \\
\hline human & men & elderly & $\begin{array}{l}\text { elevated serum } \\
\text { testosterone level }\end{array}$ & & delayed & acute & 7 \\
\hline rat & male & young & & $\begin{array}{c}\text { local application of } \\
\text { estrogen }\end{array}$ & accelerated & acute & 32 \\
\hline mice & male & young & castrated & $\begin{array}{c}\text { systemic } 17-\text { beta estra- } \\
\text { diol }\end{array}$ & delayed & acute & 13 \\
\hline mice & male & young & intact & $\begin{array}{c}\text { systemic } 17-\text { beta estra- } \\
\text { diol }\end{array}$ & impeded & acute & 13 \\
\hline mice & male & young & intact & $\begin{array}{c}\text { local application of } \\
\text { estrogen }\end{array}$ & $\begin{array}{c}\text { delayed } \\
\text { reepithelialisation } \\
\text { of cornea }\end{array}$ & acute & 35 \\
\hline
\end{tabular}

OVX — ovariectomized; HRT — hormonal replacement therapy; DHEA dehydroepiandrosterone

\section{RISKS OF ESTROGEN}

\section{REPLACEMENT THERAPY}

Although estrogen replacement is beneficial for cutaneous wound healing, its long term use is unfortunately associated with serious health risks, such as, increased risks of cerebral vascular accidents, breast cancer, venous thromboembolism, etc. $[2,30]$. Therefore, further studies need to be conducted to find a safer way of estrogen replacement therapy with less side effects. 


\section{PRECURSOR OF SEX HORMONES REPLACEMENT THERAPY}

Dehydroepiandrosterone (DHEA) is a precursor of both androgenic and estrogenic effector molecules and is synthesized in the adrenal cortex [5]. In humans, circulating levels of DHEA and its sulfate ester, DHEA sulfate (DHEAS), decrease progressively with age [20]. This is in contrast to other adrenal steroids such as glucocorticoids, in which serum levels remain relatively well-preserved with age [20]. However, adrenal DHEA production is very modest in rodents [31]. Despite this fact, rodents possess the necessary enzymatic machinery to convert exogenous DHEA to sex steroids [21]. Numerous animal studies have demonstrated several beneficial effects of DHEA administration in preventing obesity, diabetes, and heart disease, in enhancing the immune system, and even in prolonging the life-span [3]. Moreover, DHEA has been shown to inhibit breast cancer and to stimulate positive estrogenic actions, such as increased bone mineral density without predisposing to endometrial cancer [26]. Thus, the advantage of DHEA treatment compared to estrogen and androgens systemic replacement is that DHEA is only converted to its active metabolites in the specific target tissues where the appropriate enzymatic machinery does exist; thus, the adverse effects of systemic hormone treatments are eliminated [26]. In the context of skin wound healing, the systemic treatment with DHEA accelerates wound healing in young OVX female mice and old male mice [26]. Since the blockade of DHEA conversion to estrogen by aromatase inhibitor stopped wound healing improvement and the administration of androgen receptor antagonist did not, Mills et al. [26] have suggested that DHEA acts via its conversion to estrogen. Of note, DHEA has no observable effects in young animals. This may reflect an adequate level of circulating estrogens in young animals as well as that a supra-physiological local estrogen levels via DHEA conversion exert no effects on wound healing [26]. However, in study conducted on mice subjected to thermal injury, the subcutaneous administration of DHEA dramatically limited the extent of tissue necrosis. DHEA, 17-alpha-hydroxypregnenelone, 16-alpha-bromo-DHEA, and androstenediol, demonstrated comparable level of protection. On the other hand, other forms of steroids, including DHEA sulfate, androstenedione, 17- $\beta$-estradiol, or dihydrotestosterone, exhibited no protective effects [4]. These results have suggested that DHEA possess regulatory functions of its own in the context of cutaneous wound healing at least in the model of thermal injury [4].

\section{EFFECT OF ANDROGENS ON WOUND HEALING}

Whereas estrogen and DHEA positively influence skin repair, androgens rather seems to delay the healing process. The healing of full-thickness incisions is markedly accelerated in young castrated male mice compared with age-matched controls [7]. Gilliver et al. [12] have also revealed that castration or androgen receptor (AR) blockade improves healing in rodents. In the clinical setting in human medicine, elevated serum testosterone levels were correlated with delayed healing of excisional punch wounds in a group of health status-defined elderly men [7]. Because studies using androgen ablation through castration or AR blockade provide no information on the specific androgen species influencing repair, Gilliver et al. [12] subjected rats treated with the 5-a-reductase inhibitor MK434, which blocks conversion of testosterone to dihydrotestosterone (DHT), to incisional wounding in parallel with castrated animals, in which systemic production of both DHT and testosterone is abolished. Since wound repair has been accelerated to a similar extent in castrated and MK434-treated animals, it has been suggested that DHT, rather than testosterone, is responsible for the apparent inhibition of healing by androgens [12].

\section{SEX HORMONES AND CHRONIC WOUNDS}

At present, the exact roles of sex steroid hormones in the development of chronic wounds remains unclear, but current evidence suggest on the one hand that being male is a risk factor for venous ulceration and on the other hand, that the use of HRT by elderly women reduces the risk of ulceration [24]. Moreover, Gilliver et al. [12] recorded that circulating DHT levels have been shown to be significantly increased in a group of elderly male patients with venous ulcers compared with healthy age-matched control subjects. From this point of view it may be suggested that DHT have important roles in delayed cutaneous wound healing in males. 


\section{CONCLUSIONS}

Cutaneous wound healing is influenced by many factors and the importance of sex steroid hormones is evident. This fact supports, in addition to clinical observation and animal research, the localization of androgen and estrogen receptors in the skin [28]. In general, the hypoestrogenismus in female is associated with impaired wound healing and in male the maintenance of testosterone and DHT along with a decline of estrogen level is associated with impairment of skin repair [19]. Possibly this issue has led to experimental estrogen therapy also in males alone or with castration. Otherwise, the topical application of estrogen accelerates skin wound healing also in males [32]. On the contrary, Gilliver et al. [13] reported that systemic $17-\beta$ estradiol treatment delays both wound re-epithelialization and the progressive reduction of wound area in castrated males. Estrogen similarly impeded healing in intact animals; even though, they declared that sex steroids masked the fundamental underlying differences in the ways that males and females heal acute wounds. These differences include marked dimorphism in the responses to macrophage migration inhibitory factor (which inhibits repair in females only) and testosterone (an inhibitor of repair in males but not females) [13]. The study of the effect of the local estrogen therapy on healing the cornea has revealed similar detrimental results on re-epithelialization [35]. Accordingly, the estrogen therapy of skin repair in male seems to be rather inappropriate. Nevertheless, it must not mean that estrogen is not implicated in the process of wound healing in males. Of note, not all aging individuals with severe venous reflux, which is considered as a causative factor of venous ulcer development, go on to develop a venous ulcers, and recent research has identified a genetic component on ER- $\beta$ gen associated with this disease [9].

Many studies, on the rodent model, have been done in the wound healing research for human requirements, but current data suggest that further work need to be performed to better understand the underlying gender-specific mechanism of wound healing. In the field of small animal veterinary medicine, the information about the effects of sex steroid hormones on the wound healing is lacking despite the fact that many young companion animals are castrated, even sometimes they are castrated during prepubertal age. Unfortunately, interest of the effects of castration is focused on cancer, obesity and incontinence occurrence, and hair coat quality rather than changes in skin properties, impaired wound healing and chronic wound occurrence.

\section{REFERENCES}

1. Anaya, D.A., Dellinger, E.P., 2006: The obese surgical patient: a susceptible host for infection. Surg. Infect. (Larchmt), $7,473-480$.

2. Anderson, G.L., Limacher, M., Assaf, A.R., Bassford, T., Beresford, S.A., Black H. et al., 2004: Effects of conjugated equine estrogen in postmenopausal women with hysterectomy: the Women's Health Initiative randomized controlled trial. JAMA, 291, 1701-1712.

3. Angele, M.K., Catania, R.A., Ayala, A., Cioffi, W.G., Bland, K.I., Chaudry, I. H., 1998: Dehydroepiandrosterone: An inexpensive steroid hormone that decreases the mortality due to sepsis following trauma-induced haemorrhage. Arch. Surg., 133, $1281-1288$.

4. Araneo, B. A., Ryu, S. Y., Barton, S., Daynes, R. A., 1995: Dehydroepiandrosterone reduces progressive dermal ischemia caused by thermal injury. J. Surg. Res., 59, 250-262.

5. Arvat, E., Di Vito, L., Lanfranco, F., Maccario, M., Baffoni, C., Rossetto, R. et al., 2000: Stimulatory effect of adrenocorticotropin on cortisol, aldosterone, and dehydroepiandrosterone secretion in normal humans: dose-response study. J. Clin. Endocrinol. Metab., 85, 3141-3146.

6. Ashcroft, G. S., Dodsworth, J., van Boxtel, E., Tarnuzzer, R. W., Horan, M. A., Schultz, G.S. et al., 1997: Estrogen accelerates cutaneous wound healing associated with an increase in TGF- $\beta 1$ levels. Nat. Med. 3, 1209-1215.

7. Ashcroft, G. S., Mills, S. J. 2002: Androgen receptor mediated inhibition of cutaneous wound healing. J. Clin. Invest., 110, $615-624$

8. Ashcroft, G.S., Mills, S. J., Lei, K., Gibbons, L., Jeong, M. J., Taniguchi, M. et al., 2003: Estrogen modulates cutaneous wound healing by downregulating macrophage migration inhibitory factor. J. Clin. Invest., 111, 1309-1318.

9. Ashworth, J. J., Smyth, J. V., Pendleton, N., Horan, M., Payton, A., Worthington, J. et al., 2005: The dinucleotide (CA) repeat polymorphism of estrogen receptor beta but not the dinucleotide (TA) repeat polymorphism of estrogen receptor alpha is associated with venous ulceration. J. Steroid Biochem. Mol. Biol., 97, 266-270

10. Emmerson, E., Campbell, L., Ashcroft, G.S., Hardman, M. J., 2010: The phytoestrogen genistein promotes wound healing 
by multiple independent mechanisms. Mol. Cell Endocrinol., 321, 184-193.

11. Gantwerker, E. A., Hom, D. B., 2011: Skin: histology and physiology of wound healing. Facial Plast. Surg. Clin. North Am., 19, 441-453.

12. Gilliver, S. C., Ashworth, J. J., Mills, S. J., Hardman, M. J., Ashcroft, G.S., 2006: Androgens modulate the inflammatory response during acute wound healing. J. Cell Sci. 119, Pt 4, 722-732.

13. Gilliver, S. C., Emmerson, E., Campbel, L., Chambon, P., Hardman, M.J., Ashcroft, S. G., 2010: $17 \beta$-estradiol inhibits wound healing in male mice via estrogen receptor- $\alpha$. Am. J. Pathol., 176, 2707-2721.

14. Gosain, A., DiPietro, L.A., 2004: Aging and wound healing. World J. Surg., 28, 321-326.

15. Guo, S., DiPietro, L.A., 2010: Factors affecting wound healing. J. Dent. Res., 89, 219-229.

16. Hardman, M.J., Ashcroft, G.S., 2008: Estrogen, not intrinsic aging, is the major regulator of delayed human wound healing in the elderly. Genome Biol., 9, 1-17. doi:10.1186/gb2008-9-5-r80, http://genomebiology.com/2008/9/5/R80.

17. Hardman, M. J., Emmerson, E., Campbell, L., Ashcroft, G.S., 2008: Selective estrogen receptor modulators accelerate cutaneous wound healing in ovariectomized female mice. Endocrinology, 149, 551-557.

18. Holcomb, V. B., Keck, V. A., Barret, J. C., Hong, J., Libtti, S.K., Nunez, N.P., 2009: Obesity impairs wound healing in ovariectomized female mice. In vivo, 23, 515-518.

19. Labrie, F., Belanger, A., Cusan, L., Gomez, J. L., Candas, B., 1997: Marked decline in serum concentrations of adrenal c19 sex steroid precursors and conjugated androgen metabolites during aging. J. Clin. Endocrinol. Metab., 82, 2396-2402.

20. Labrie, F., Belanger, A., Luu-The, V., Labrie, C., Simard, J., Cusan, L. et al., 1998: DHEA and the intracrine formation of androgens and estrogens in peripheral target tissues: Its role during aging. Steroids, 63, 322-328.

21. Labrie, F., Luu-The, V., Lin, S.X., Simard, J., Labrie, C., El-Alfy, M. et al., 2000: Intracrinology: role of the family of $17-\beta$ hydroxysteroid dehydrogenases in human physiology and disease. Journal of Molecular Endocrinology, 25, 1-16.

22. Lemieux, C., Picard, F., Labrie, F., Richard, D., Deshaies, Y., 2003: The estrogen antagonist EM-652 and dehydroepiandrosterone prevent diet- and ovariectomy-induced obesity. Obes. Res. 11, 477-490.

23. Li, J., Chen, J., Kirsner, R., 2007: Pathophysiology of acute wound healing. Clinics in Dermatology, 25, 9-18.
24. Margolis, D. J., Knauss, J., Bilker, W., 2002: Hormone replacement therapy and prevention of pressure ulcers and venous leg ulcers. Lancet, 359, 675-677.

25. Mathieu, D., Linke, J.C., Wattel, F., 2006: Non-healing wounds. In Mathieu, D. E. (Ed.): Handbook on Hyperbaric Medicine, Netherlands: Springer, 401-427.

26. Mills, S. J., Ashworth, J.J., Gilliver, S.C., Hardman, M. J., Aschcroft, G.S., 2005: The sex steroid precursor DHEA accelerates cutaneous wound healing via the estrogen receptors. J. Invest. Dermatol., 125, 1053-1062.

27. Pavletic, M. M., 2010: Basic principles of wound healing. In Atlas of Small Animal Wound Management and Reconstructive Surgery, 3rd edn., Wiley-Blackwell, 17-29.

28. Pelletier, G., Ren, L., 2004: Localization of sex steroid receptors in human skin. Histol. Histopathol., 19, 629-636.

29. Pospíśilová, A., 2011: New views on healing and treatment of wounds (In Czech). Practicus, 10, 27-30.

30. Prentice, R.L., Manson, J.E., Langer, R. D., Anderson, G. L., Pettinger, M., Jackson, R. D. et al., 2009: Benefits and risks of postmenopausal hormone therapy when it is initiated soon after menopause. Am. J. Epidemiol., 170, 12-23.

31. Punjabi, U., Deslypere, J.P., Verdonck,. L, Vermeulen, A., 1983: Androgen and precursor levels in serum and testes of adult rats under basal conditions and after HCG stimulation. J. Steroid Biochem., 19, 1481-1490.

32. Rajabi, M. A., Rajabi, F., 2007: The effect of estrogen on wound healing in rats: 2007. Pak. J. Med. Sci., 23, 349-352.

33. Robson, M.C., Steed, D.L., Franz, M. G., 2001: Wound healing: biologic features and approaches to maximize healing trajectories. Curr. Probl. Surg., 38, 72-140.

34. Velnar, T., Bailey, T., Smrkoj, V., 2009: The wound healing process: an overview of the cellular and molecular mechanism. Journal of International Medical Research, 37, 1528-1542.

35. Wang, S. B., Hu, K. M., Seamon, K. J., Mani, V., Chen, Y., Gronert, K., 2012: Estrogen negatively regulates epithelial wound healing and protective lipid mediator circuits in the cornea. The FASEB Journal, 26, 1506-1516.

36. Wu, J., Wang, X., Chiba, H., Higuchi, M., Nakatani, T., Ezaki, O. et al., 2004: Combined intervention of soy isoflavone and moderate exercise prevents body fat elevation and bone loss in ovariectomized mice. Metabolism, 53, 942-948.

Received November 23, 2015 